\title{
Sampling-rate effects on the properties of dye breakthrough curves from glaciers
}

\author{
Peter W. Nienow \\ Department of Geography, University of Edinburgh, Drummond Street, Edinburgh EH8 9XP, Scolland \\ MARTIN SHARP \\ Department of Geography, University of Alberta, Edmonton, Alberta T6G 2H4, Canada \\ IAN C. WiLLiS \\ Department of Geography, University of Cambridge, Downing Place, Cambridge CB2 3E. N, England
}

\begin{abstract}
Dye-tracer techniques are widely used to infer the character of subglacial drainage systems. Quantitative analysis of dye breakthrough curves focuses on the determination of the water throughflow velocity $(u)$, the dispersion coefficient $(D)$ and the dispersivity parameter $(d=D / u)$. Together, these parameters describe the rate of passage of tracer through the drainage system and the extent to which the dye cloud becomes spread out during passage. They have been used to infer the nature of flow conditions within a drainage system and temporal changes in system morphology. Estimates of all three parameters, however, are dependent upon the sampling interval at which measurements of dye concentration used to define breakthrough curves are made. For a given breakthrough curve, the dispersion coefficient increases with the sampling interval, while the throughflow velocity shows no systematic variation. As a result, the dispersivity also tends to increase with the sampling interval. Investigations of the sensitivity of parameter estimates to the sampling interval reveal that reliable estimates can be obtained only if the sampling interval is less than $1 / 16$ of the time from dye injection to peak dye concentration. As a general guide, we suggest that, ideally, quantitative analyses of dye breakthrough curves should therefore be conducted only when this criterion can be met.
\end{abstract}

\section{INTRODUCTION}

With the realisation that there may be a strong coupling between the hydrology of warm-based glaciers and their flow mechanics (Iken, 1981), there has arisen a strong interest in determining the morphology of subglacial drainage systems and its evolution over time (Kamb and others, 1985; Seaberg and others, 1988; Willis and others, 1990; Fountain, 1993; Hock and Hooke, 1993; personal communication from P. Nienow, I. Willis, M. Sharp and K. Richards, 1994). Tracer techniques have been widely used for this purpose, and are perhaps the best method available for determining drainage-system characteristics on a glacier-wide scale (Hooke, 1989).

Tracing involves the injection of a known quantity of tracer (salt, or more commonly a fluroescent dye such as rhodamine (B or WT) or fluorescein) at a known point commonly a moulin or crevasse on the glacier surface, but occasionally the base of a borehole drilled to the glacier bed), and its detection in one or more meltwater streams draining from the glacier. Three forms of detection are widely practised:

1. Activated charcoal detectors are placed in the stream and absorb dye as it passes. After completion of a test, the detector is rinsed in an eluent which is then passed through a fluorometer. The presence or absence of dye is used to determine whether or not dye emerged in a particular stream (e.g. Smart and Brown, 1973).

2. Discrete samples of stream water are collected and run through a fluorometer to measure dye concentration (e.g. Seaberg and others, 1988).

3. Water drawn from the stream is passed continuously through a fluorometer, and dye concentrations are recorded on a data logger or chart recorder (e.g. Fountain, 1993).

Methods 2 and 3 allow the construction of dye breakthrough curves (plots of dye concentration vs time).

Quantitative analyses of dye breakthrough curves form the basis of modern dye-tracing techniques (Smart, 1988). However, the success of such analyses is strongly dependent upon the accuracy with which the breakthrough curve is resolved (Fischer, 1968; Behrens and others, 1975). This is a function of the accuracy of the fluorometric detection procedures employed and the frequency with which water samples are collected for analysis of dye concentration. In this paper we consider the influence of the sampling interval on the determination and interpretation of the properties of dye breakthrough curves. Our goal is to determine the minimum sampling frequency which allows consistent determination of these properties. 


\section{METHODS USED IN THE ANALYSIS OF DYE BREAKTHROUGH CURVES}

In this section, we identify the parameters most commonly employed in quantitative analyses of dye breakthrough curves, in order to show how an accurate determination of the form of the breakthrough curve is essential to the accurate estimation of these parameters.

Establishing the time between dye injection and peak concentration in an outflow stream $\left(t_{\mathrm{m}}\right)$ allows estimation of the flow velocity, $u$, through a glacial drainage system distance travelled $\left./ t_{\mathrm{m}}\right)$. This provides information concerning the hydraulic structure of the flow system. Rapid flow velocities $\left(>0.2 \mathrm{~m} \mathrm{~s}^{-1}\right)$ have been interpreted as indicating flow through hydraulically efficient channelised drainage systems Stenborg, 1969; Krimmel and others, 1973; Behrens and others, 1975; Moser and Ambach, 1977; Lang and others, 1979; Burkimsher, 1983). Lower flow velocities have usually been interpreted as indicating flow through a hydraulically inefficient "distributed" hydrological system such as a linked-cavity configuration, a thin basal water film or a permeable basal sediment layer (Theakstone and Knudsen, 1981; Iken and Bindschadler, 1986; Kamb, 1987; Willis and others, 1990). In some recent work, velocities of less than $0.1 \mathrm{~ms}$ ' have been interpreted as indicating flow through highly sinuous, hydraulically inefficient, anabranching channels Fountain, 1993; Hock and Hooke, 1993).

The shape of a dye breakthrough curve provides information about the flow conditions within the system traced, particularly with regard to the mechanisms which cause dispersion of the dye cloud. An increasingly dispersed dye cloud can result from two main effects: (i) an increase in the range of flow velocities within the drainage path which will enhance mechanical dispersion); and (ii) an increase in the number of storage locations or immobile zones along the drainage path (which will enhance molecular diffusion). In general, dispersion resulting from variations in flow velocity is the dominant factor in channelised systems, whilst dispersion resulting from storage retardation becomes increasingly significant in distributed-flow systems. Two parameters are widely used to describe the degree of dispersion of a breakthrough curve: the dispersion coefficient, $D$, (Taylor, 1954; Levenspiel and Bischoff, 1963) and the dispersivity, $d$ Fischer, 1968; Behrens and others, 1975).

The dispersion coefficient, $D$, is used to describe the rate of dispersion of a dye cloud during its passage through a drainage system. It has units of $\mathrm{m}^{2} \mathrm{~s} !$. There are numerous methods of obtaining $D$ from a dye breakthrough curve. Within glaciology, a detailed analysis of the processes of dispersion was undertaken by Brugman (1986). One of the methods used by her and subsequently by Seaberg and others (1988) and Willis and others $(1990)$ to derive a value of $D$ is used here:

$$
D=x^{2}\left(t_{\mathrm{m}}-t_{i}\right)^{2} / 4 t_{\mathrm{m}}{ }^{2} t_{i} \ln \left[2\left(t_{\mathrm{m}} / t_{i}\right)^{\frac{1}{2}}\right] .
$$

Here, $x$ is the straight-line distance between the points of dye injection and recovery, $t_{\mathrm{m}}$ is the time to maximum dye concentration but is not taken from field data, but instead is treated as a variable to be obtained in the solution), and $t_{i}$ represents $t_{1}$ and $t_{2}$, which are the times when the dye concentration reaches half its peak value on the rise to and decline from the concentration peak. Equation (1) represents two equations for $i=1,2$ and is solved iteratively for $t_{\mathrm{m}}$ until a value is chosen such that the two equations are satisfied and $D$ is obtained. Unfortunately, because $D$ is dependent upon both the mean flow velocity and the range of flow velocities within the drainage system it does not, on its own, provide a reliable insight into drainage-system structure. It is therefore usual to look also at the relationship between $D$ and the mean flow velocity determined from a tracer test.

In a given channel with a constant roughness and hydraulic radius, it has been found that $D$ is approximately proportional to the average flow velocity, $u$ Fischer, 1968; Behrens and others, 1975; Maloszewski, 1992), such that:

$$
D \sim d u .
$$

Here, $d$ is referred to as the dispersivity and has units of m. Hock and Hooke (1993, p. 544) state that "of the parameters derived from analysis of dye-return curves, the dispersivity is the one that most clearly illustrates evolution of the drainage system" at Storglaciären, Sweden, during the summer 1989 melt season.

The interpretation of dispersivity values derived from tracer tests in glacier drainage systems is discussed more fully elsewhere personal communication from P. Nienow, I. Willis, M. Sharp and K. Richards, 1994). For our present purposes, it suffices to say that the dispersivity represents the rate of spreading of a dye cloud relative to the rate of advection of the dye during transit through a flow system, and that it provides a measure of a length scale characteristic of the drainage system (Fischer, 1968; Gillham and others, 1984). An accurate estimate of $d$ can only be obtained if $D$ and $u$ are well known. To achieve this, it is necessary to have a well-defined breakthrough curve so that the values of $t_{\mathrm{m}}$ and $t_{i}$ (Equation (1)) obtained from the curve and used in the calculation of $u$ and $D$ are correct or have an acceptable error margin. The importance of this was acknowledged by Fischer 1968 and Behrens and others $(1975$, p. 381 ), the latter noting that, in certain tracing experiments at the Hintereisferner, Austria, the sampling interval was "comparatively long as compared to the time of passage of a tracer cloud", and "the amount of data was therefore too small for a dispersion analysis". At the Hintereisferner, a 5 min sampling interval was used whilst the passage of a dye cloud often took no more than 15 $20 \mathrm{~min}$. For detailed dispersion studies, a shorter sampling interval was required to generate a more accurate breakthrough curve and thus more accurate values of $D$ and $u$. We now seek to determine how short this sampling interval must be.

\section{SAMPLING-RATE EFFECTS ON THE DETERMIN- ATION OF VALUES FOR THE FLOW VELOCITY, DISPERSION COEFFICIENT AND DISPERSIVITY}

In this section, we evaluate the sensitivity of values of $u, D$ and $d$ to variations in the sampling interval used to define a dye breakthrough curve. To do so, we make use of breakthrough curves resulting from injections made into moulins on Haut Glacier d'Arolla, Valais, Switzer- 
land during the summer of 1990. The tracer used was rhodamine $\mathrm{B}$, and dye detection was by continuous flow fluorometry using a Turner Designs 10-005 field fluorometer. Full details of the methods employed are given by Sharp and others (1993).

To illustrate the dependence of values of $u, D$ and $d$ on the sampling interval, we consider a series of breakthrough curves which resulted from ten injections conducted at a moulin located $1.44 \mathrm{~km}$ from the glacier snout on 14 August (Fig. la). These curves were generated by $1 \mathrm{~min}$ averaging of dye concentrations measured every 10 s using a Campbell Scientific Limited $21 \mathrm{X}$ data logger. The curves were sub-sampled to produce breakthrough curves based on dye concentrations taken at 5 and $10 \mathrm{~min}$ intervals (Fig. $1 \mathrm{~b}$ and c). Values of time to peak dye concentration $\left(t_{\mathrm{m}}\right), u, D$ and $d$ obtained from each set of curves are given in Table 1.

The shape of the breakthrough curve generated by a given injection becomes increasingly angular as the sampling interval is increased, whilst the detail of the curve is lost (Fig. 1). The general shape of a breakthrough curve remains relatively consistent as the sampling interval is increased, but the peakedness of individual curves tends to decrease as the short-lived dye-concentration peak is missed. In the case of injection 3, the breakthrough curve resulting from the $10 \mathrm{~min}$ sampling interval is very different from that produced with shorter sampling intervals.

Although there are no systematic variations in the values of $u$ obtained from breakthrough curves constructed with different sampling intervals, it is clear that the values obtained with 5 and $10 \mathrm{~min}$ sampling intervals rarely coincide with those obtained with a 1 min sampling interval (Fig. 2a; Table 1). The mean value of $D$ obtained from $1 \mathrm{~min}$ sampling was $2.81 \mathrm{~m}^{2} \mathrm{~s}^{-1}$ (standard deviation (S.D.) $=0.70$. Such consistent results are to be expected from a series of closely spaced injections made into a single moulin over a period of time that is short enough to assume a "constant" drainage configuration. Sampling intervals of 5 and $10 \mathrm{~min}$ produced mean $D$ values of 4.15 $($ S.D. $=2.04)$ and $9.54($ S.D. $=7.06) \mathrm{m}^{2} \mathrm{~s}^{1}$, respectively. These larger and more variable values (Fig. 2b), which might be taken to suggest significant changes in the drainage-system morphology during the course of a single day, clearly result from inadequate definition of the breakthrough curve rather than from actual changes in the drainage configuration.

Since $D$ tends to increase with the sampling interval, whilst $u$ shows no systematic variation, it follows that $d$ also tends to increase as the sampling interval increases. The dispersivity values determined from the 1,5 and $10 \mathrm{~min}$ data sets by regressing $D$ on $u$ (forcing the regression to omit a constant) were, respectively, 5.28 $\left(r^{2}=0.57, p<0.005\right), 7.93\left(r^{2}=0.03\right)$ and 17.92 $\left(r^{2}=0.04\right)$ (Fig. 2c). These results suggest that a $5 \mathrm{~min}$ sampling interval is too great to obtain an accurate estimate of $d$ from the breakthrough curves resulting from the series of injections conducted on 14 August 1990.

In order to determine the precise sampling interval required to generate accurate estimates of $D$ and thus $d$, the curves were further sub-sampled at 2, 3 and 4 min intervals. Figure $2 \mathrm{~d}$ shows that certain values of $D$ increase markedly from the $1 \mathrm{~min}$ sampling-interval estimates when the sampling interval is increased from 3 to $4 \mathrm{~min}$. This fact is
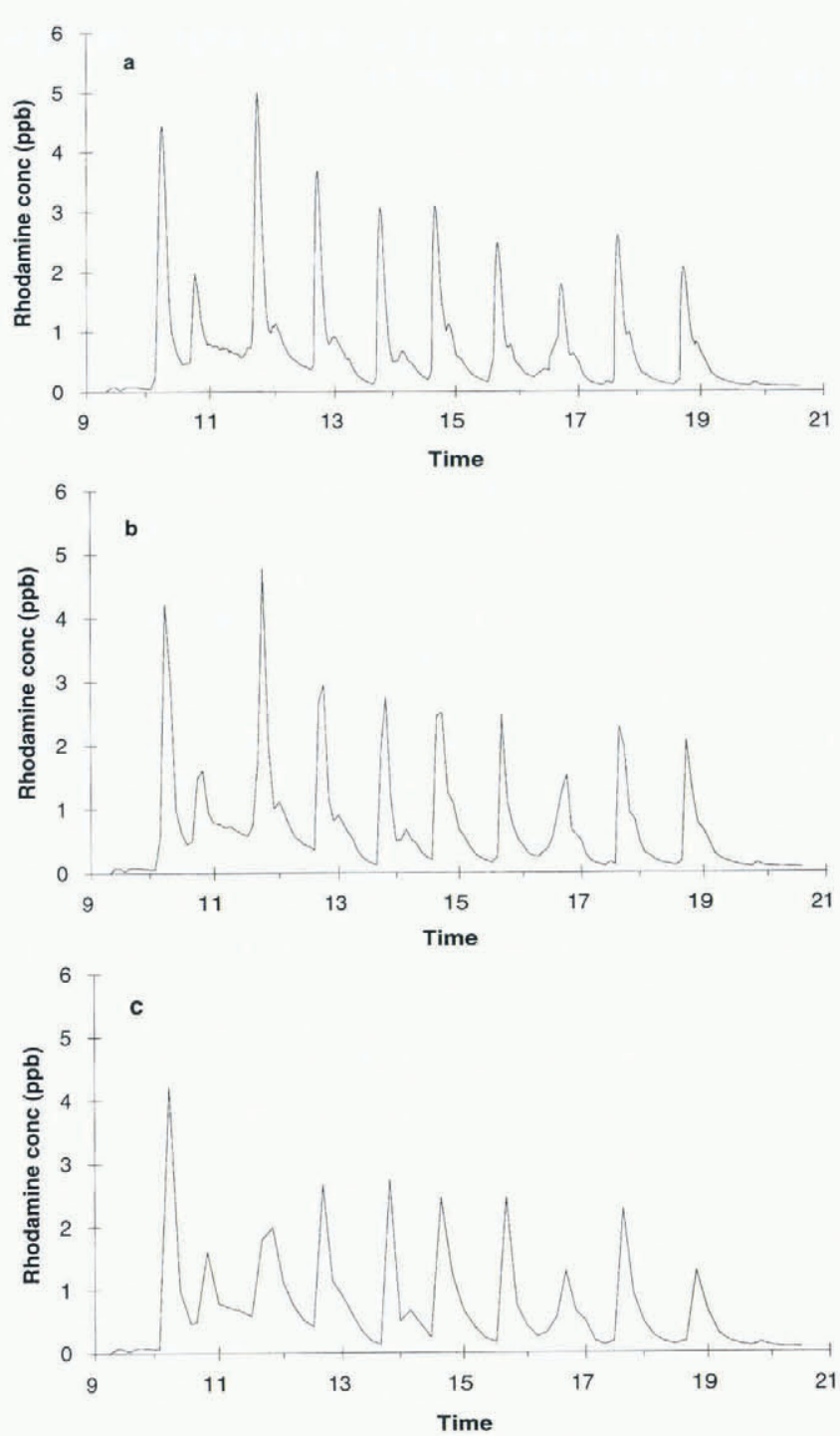

Fig. 1. A series of dye breakthrough curves resulting from ten injections conducted at a moulin located $1.44 \mathrm{~km}$ from the snout of Haut Glacier d'Arolla, Valais, Swizerland, on 14 August 1990. Curves are plotted for sampling intervals of (a) 1, (b) 5 and (c) $10 \mathrm{~min}$.

further illustrated by the standard deviation derived from the ten estimates of $D$ which is 0.70 for $1 \mathrm{~min}$ sampling, and increases from 0.82 to 1.33 for the 3 and 4 min sampling intervals, respectively (Table 2). Similarly, the correlation coefficient obtained from regressing $D$ on $u$ to obtain $d$ decreases from $0.43(p<0.025)$ to 0.23 between the 3 and 4 min sampling intervals (Table 2 ).

Thus, in the above example, in which the dye-return times were all less than $62 \mathrm{~min}$ and the passage of over $90 \%$ of the recovered tracer took no more than $20 \mathrm{~min}$, a sampling interval of $3 \mathrm{~min}$ or less was required to prevent erroneous values of $d$ being derived from the breakthrough curves. However, the sampling interval required to produce a breakthrough curve that is defined well enough to allow accurate estimation of $d$ will increase as the time of passage of a tracer cloud and/or the distance travelled by the tracer increases. This is a simple reflection of the rate of change of concentrations during a dye return, which tends to decrease as the tracer cloud becomes more dispersed.

To illustrate this, we consider how varying the 
Table 1. Effects of variations in the sampling interval on throughflow velocity, dispersion coefficient and dispersivity for a series of tests underlaken at a moulin $1.44 \mathrm{~km}$ from the snout of Haul Glacier d'Arolla on 14 August 1990

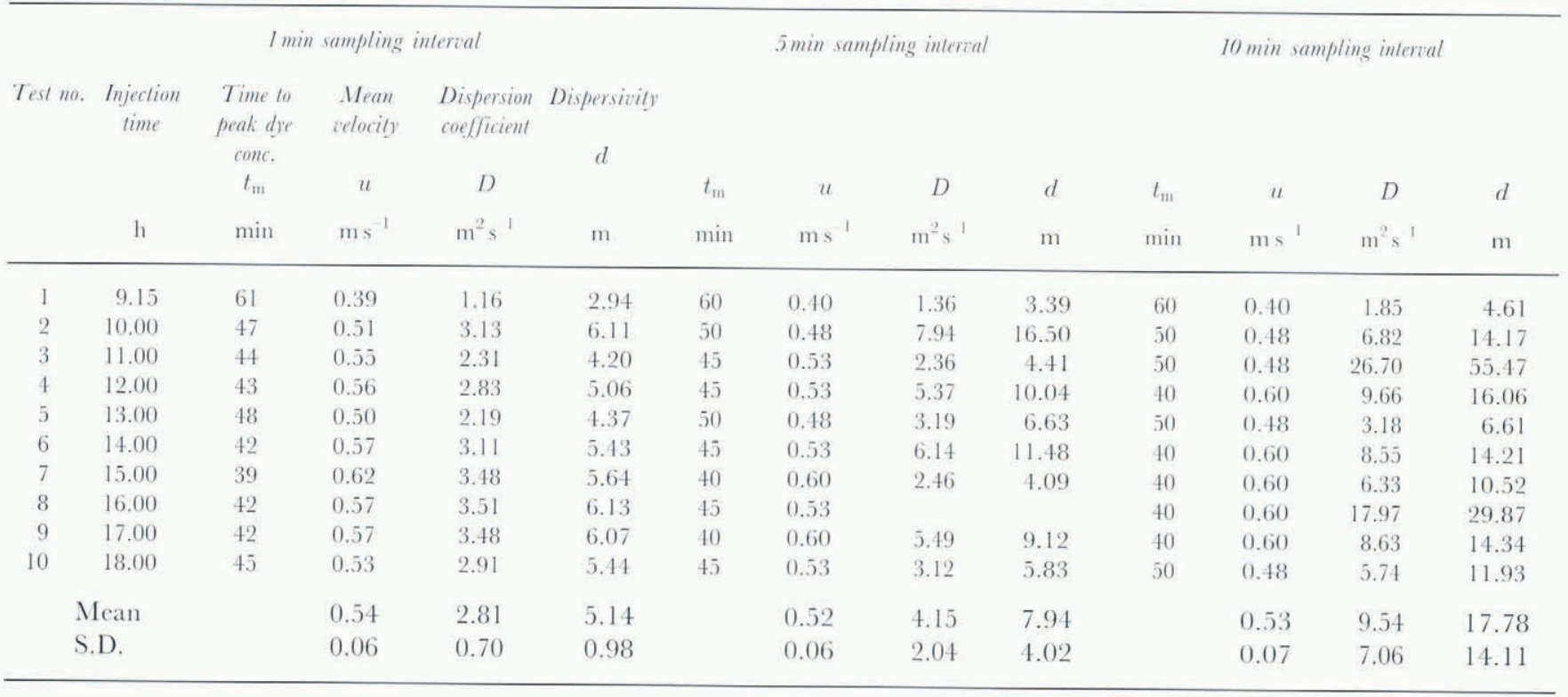

sampling interval affects estimates of $u, D$ and $d$ derived from an additional six breakthrough curves resulting from tracer tests conducted during the 1990 melt season. The time to peak dye concentration in these experiments varied between 81 and $267 \mathrm{~min}$ (Table 3 ). Figure 3 shows how the value of $D$ derived from the breakthrough curve varies with sampling interval for each of the six injections.
For each curve, the point at which $D$ begins to increase with sampling interval is taken to indicate the maximum possible sampling interval which will allow acceptable estimates of $D$ and $d$ to be made. The ratio of the spread of the return curve characterised by the time between half-peak concentration on the rising and falling limbs of the curve) to maximum allowable sampling interval
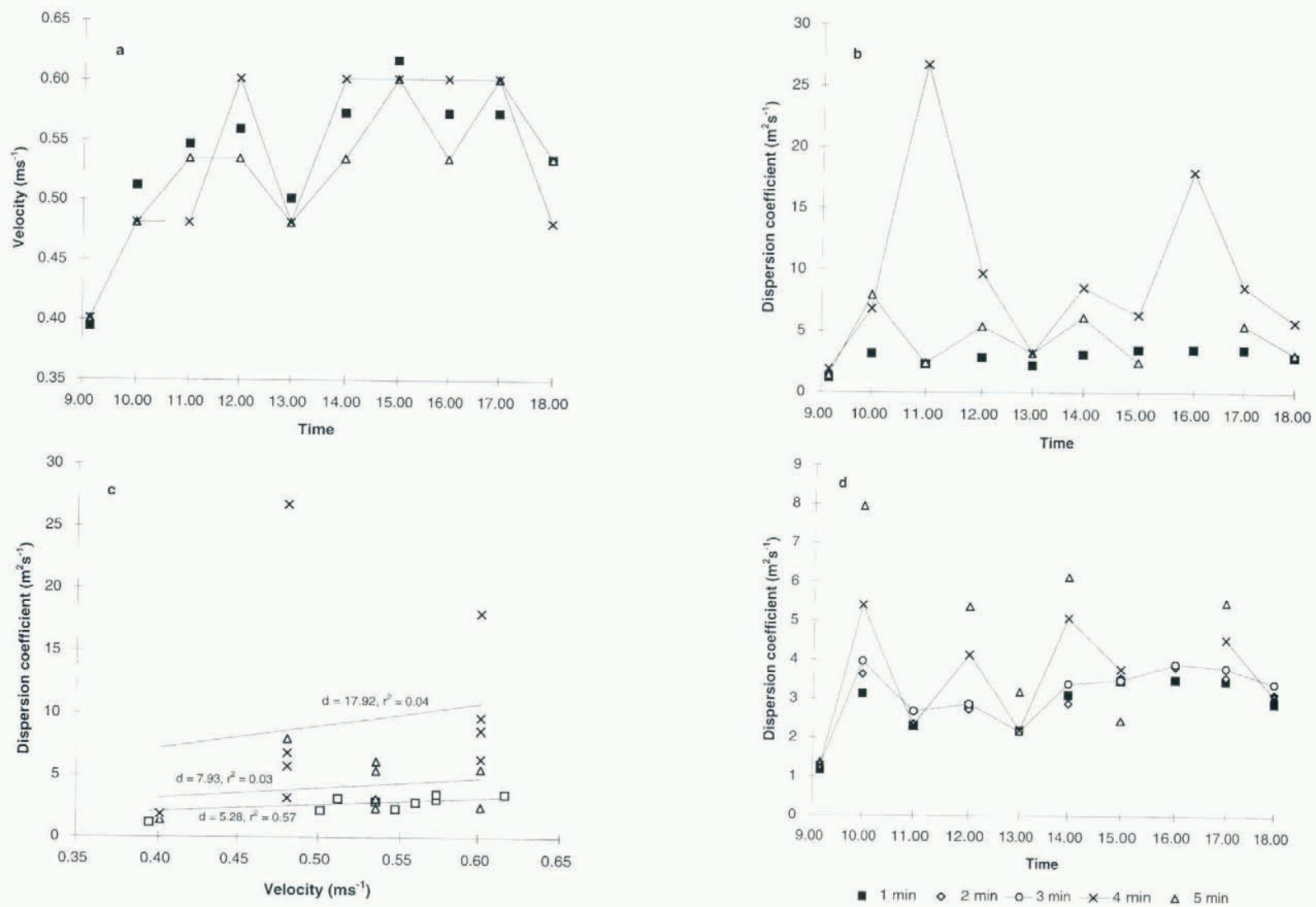

Fig. 2. Variations in (a) the throughflow velocity, $u$, and (b) the dispersion coefficient, D, determined from ten breakthrough curves resulling from dye injections conducted at a moulin located $1.44 \mathrm{~km}$ from the snout of Haut Glacier d'Arolla on 14 . August 1990 as a function of the sampling interval used to construct the breakthrough curve. (c) A plot of D against u for the data plotted in Figure 2a and b, showing the regression lines used to estimate the dispersivity, d, for 1, 5 and 10 min sampling intervals. (d) A repeat of (b) with different sampling intervals used to determine the dispersion coefficient, $D$. 
Table 2. Effects of variations in sampling interval on the mean dispersion coefficient (D) and related variables for the ten tracer tests summarised in Table 1

\begin{tabular}{|c|c|c|c|c|}
\hline Sampling interval & $\begin{array}{l}\text { Mean dispersion } \\
\text { coefficient, } D\end{array}$ & $\begin{array}{l}\text { Standard deriation } \\
\qquad \text { of } D\end{array}$ & $\begin{array}{c}\text { Value of } d \text { determined by } \\
\text { regressing } D \text { on } u\end{array}$ & $\begin{array}{c}\text { Correlation coefficient for } \\
\text { regression of } D \text { on } u\end{array}$ \\
\hline $\min$ & $m^{2} s^{1}$ & & $\mathrm{~m}$ & $r^{2}$ \\
\hline 1 & 2.81 & 0.70 & 5.28 & $0.57(p<0.005)$ \\
\hline 2 & 2.91 & 0.78 & 5.49 & $0.44(p<0.025)$ \\
\hline 3 & 3.09 & 0.82 & 5.81 & $0.43(p<0.025$ \\
\hline 4 & 3.53 & 1.33 & 6.70 & $0.23)$ Not significant \\
\hline 5 & 4.15 & 2.04 & 7.93 & $0.03\}$ at the 0.05 \\
\hline 10 & 9.54 & 7.06 & 17.92 & $0.04 \int$ level \\
\hline
\end{tabular}

varies from 1.7 to 6.1 (Table 3 ) with a mean of 3.4 $($ S.D. $=1.7)$. The ratio of time to peak dye concentration to maximum allowable sampling interval varies from 7.3 to 16.0 (Table 3 ) with a mean of 11.2 (S.D. $=3.5$ ). Given the variability of both sets of results, $t_{\mathrm{m}}$ is considered a more appropriate parameter for establishing a suitable sampling interval due to the ease with which it can be determined in the field. Thus, if a tracer experiment is conducted with the intention of analyzing the shape of the breakthrough curve, it is advisable to adopt a sampling interval no greater than $t_{\mathrm{m}} / 16$. Greater sampling intervals are likely to result in inconsistent and inaccurate estimates of $D$, and hence of $d$.

\section{CONGLUSIONS}

The principal impact of increasing the sampling interval used to construct a dye breakthrough curve is to increase estimated values of the dispersion coefficient, D. Estimates

Table 3. The effects of variations in the sampling interval on apparent throughflow velocity, dispersion coefficient and dispersivity for six tests of varying duration conducled during the 1990 field season at Haul Glacier d'Arolla. The maximum acceptable values of $t_{2}-t_{1} / t_{\mathrm{s}}$ and $t_{\mathrm{m}} / t_{\mathrm{s}}$ before $D$ begins to increase with sampling interval are underlined

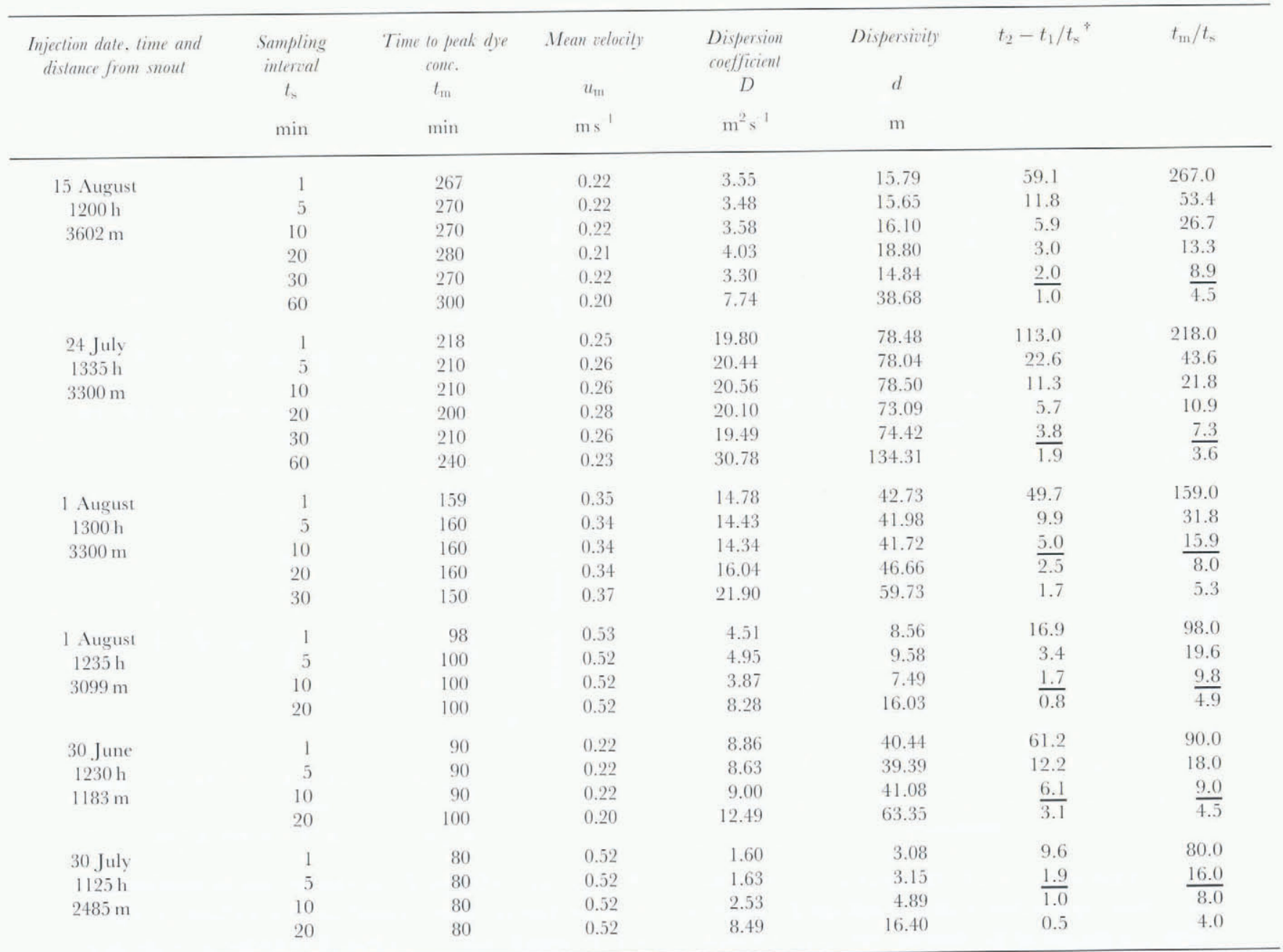

\footnotetext{
$+t_{1}$ and $t_{2}$ represent the times when the dye concentration reaches half its peak value on the rise to $\left(t_{1}\right)$ and decline from $\left(t_{2}\right)$ the concentration peak.
} 


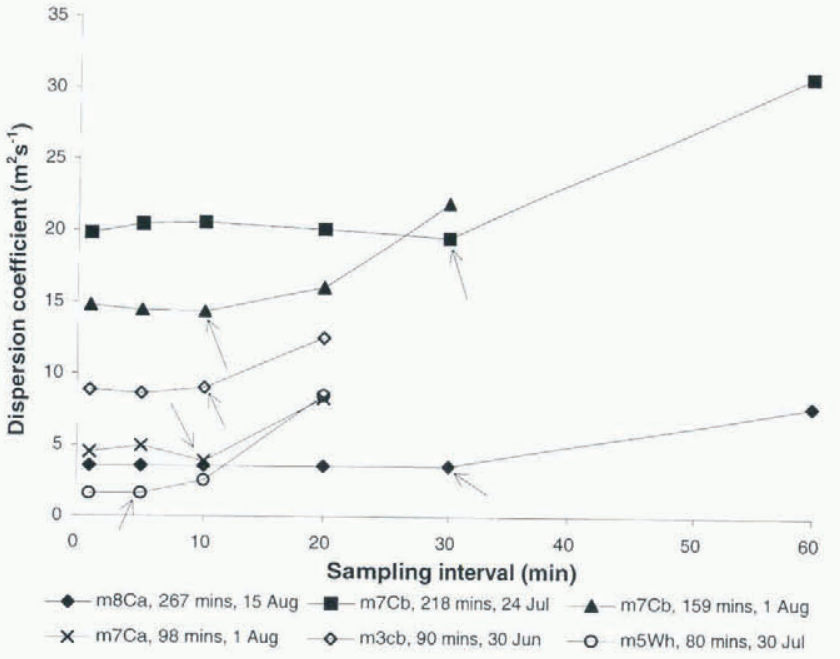

Fig. 3. Variations in the dispersion coefficient. D, determined from six breakthrough curves resulting from dye injections conducted on Haut Glacier d'Arolla in 1990 as a function of the sampling interval used to construct the breakthrough curve. The six curves were selecled on the basis of the variations in time to peak dye concentration, $t_{m}$, which they show. Arrows indicate the point for each curve at which $D$ begins to increase with sampling interval, and thus define the maximum acceptable sampling interval for that injection.

of throughflow velocity, $u$, are changed by increasing the sampling interval, but not in any consistent way. Both $D$ and $u$ are used to calculate the dispersivity, $d$, so estimates of $d$ also tend to increase with sampling interval. Since increases in $d$ have commonly been taken to indicate an increase in the complexity of glacial drainage systems, and in the number of storage locations within them, it is important to be certain that such increases are not merely an artefact of the sampling procedure used to construct dye breakthrough curves. An analysis of the variation of $D$ with sampling interval for six breakthrough curves which produced widely varying times to peak dye concentration $\left.t_{\mathrm{m}}\right)$ suggests that accurate and consistent estimates of $d$ will only be produced when the sampling interval used is $<t_{\mathrm{m}} /$ 16. Where this criterion cannot be met, caution should be applied when making inferences about the character of glacial drainage systems based on an analysis of the dispersion characteristics of dye breakthrough curves.

\section{ACKNOWLEDGEMENTS}

This work was supported by the U.K. Natural Environment Research Council through grant GR3/7004a, and by grants from Earthwatch. P. Nienow acknowledges receipt of an NERC studentship G'T4/89/AAPS/53) and Fellowship GT5/93/AAPS/1). We thank W. H. Theakstone University of Manchester) for the loan of his fluorometer, Grande Dixence SA for logistic support, and Y. Bams for all her help and support in Arolla. Field assistance was provided by $\mathrm{K}$. Richards, C. Hill, B. Hubbard, N. Anold, W. Lawson, J. Branson, J. Strike, J. -L. Tison, S. Lane, M. Skidmore, N. Spedding and 36 Earthwatch volunteers. We should also like to thank two anonymous reviewers for helpful comments on an earlier version of this paper.

\section{REFERENGES}

Behrens, H., H. Bergmamn, H. Moser. W. Ambach and O. Jochum. 1975. On the water channels of the internal drainage system of the Hintereisferner, Öztal . Mps, Austria. J. Glaciol.. 14 72) 375382.

Brugman, M. M. 1986. Water flow at the base of a surging glacier. Ph.D. thesis, California Institute of Technology, Pasadena, C.A.

Burkimsher, M. 1983. Investigations of glacier hydrological systems using dye tracer techniques: observations at Pasterzengletscher. Austria. J. Glaciol., $29103,403+16$

Fischer. H. B. 1968. Mrthods for predicting dispersion coefficients in natural streams, with applications to lower reaches of the Green and Duwamich Rivers, Washington. C.S. Geol. Surt. Pro/. Pap. 582-A.

Fountain. A. G. 1993. Geometry and flow conditions of subglacial water at South Cascade Giacier, Washington State, U.S.A.; an analysis of tracer injections. J. Glaciol., 39 131), 143-156.

Gillham, R. W.. E. . . Sudick. J.. . Cherry and E. O. Frind. 1984. In advection-diffusion concept for solute transport in heterogencous unconsolidated geological deposits. W'ater Resaur. Res., 20 3). 369-378.

Hock. R. and R. LeB. Hooke. 1993. Evolution of the internal drainage system in the lower part of the ablation area of Storglaciären, Siveden. Geol. Soc. Am. Bull., $1054,537.516$.

Hooke, R. L.eB. 1989. Englacial and subglacial hydrology: a qualitative review. Aret. 1/p. Res.. 213.221233.

Iken. A. 1981. The eflect of the subglacial water pressure on the sliding velocity of a glacier in an idealized numerical model. J. Glaciol.. 2797 , 407-421.

Iken, A. and R.A. Bindschadler. 1986. Combined measurements of subglacial water pressure and surface velocity at Findelengletscher, Switzerland: conclusions about drainage system and sliding mechanism. \%. Giaciol., 32110 . 101-119.

Kamb, B. 1987. Glacier surge mechanism based on linked cavity conliguration of the hasal water conduit system. \%. Geopltys. Res.. 92 B9, 90839100.

Kaml, B. and 7 othens. 1985. Glacier surge mechanism: 1982-1983 surge of Variegated Glacier. Mlaska. Sciener. 2274686 . 469479.

Krimmel, R. M.. W. Y. Tangborm and M. F. Meier. 1973. Water flow through at temperate glacier. Asociation of II)drological Scienes Publication 107 Sympesium at Banti 1972 The Role of Shou and lee in Hydrologr . 401 H6.

Lang. H.. (: I.eibundgut and E. Festel. 1981. Results from tracer experiments on the water flow through the Aletschgletseher, z. Giletscherkd. Cilazialgeol., $152,1979,209218$.

Levenspiel. (). and K. B. Bischoff. 1963. Patterns of thow in chemical process vessels. Adti. Chem. Eng., 4, 95-198.

Maloszewski, P. 1992. Mathematical modelling of tracer transport in different aquifers: results liom ATH test lields. In Hotzl. H. and . . Werner, eds. Tracer hydrology. Rotterdam, A. A. Balkema, 2530.

Moser, H. and W. Ambach. 1978. Glacial-hydrological investigations in the Oetzal Nps made between 1968 and 1975. Z. Ciletscherkd. Gilasialgeol.. 13 1 2, 1977, 167-179.

Seaberg, S. \%., J. \%. Seaberg, R. LeB. Hooke and D, W. Wiberg. 1988 Chatacter of the englacial and subglacial drainage system in the lower part of the ablation area of Storglaciären, Sweden, as revealed by dye-trace studies. J. Glaciol., 34 117), 217-227.

Sharp, M.J. and 6 others. 1993. Geometry, bed topography and drainage system structure of the Haut Glacier d'Arolla, Switzerland. Farth Surface Processes and Landforms, 18 6), 557571.

Smart, C. C. 1988. Artificial tracer techniques for the determination of the structure of conduit aquifers. Groundwater, 26, $445 \quad 453$.

Smart, P. L. and M. C. Brown. 1973. The use of activated carbon for the detection of the tracer dye Rhodamine WT. In Procedings, Gilh International Speleological Congress, Olomouc, L.S.S.R. Vol. 4. 285.292.

Stenborg. T. 1969. Studies of the internal drainage of glaciers. Gengr. Ani., $51 \mathbf{A}(1-2), 1341$.

Taylor, G. 1. 1954. Dispersion of matter in turbulent flow through a pipe. Proc. R. Soc. London, Ser. A, 223. 446468.

Theakstone, W. H. and N. T. Knudsen. 1981. Dye tracer tests of water movement at the glacier Austre Okstindbreen, Norway. Nor. Geogr. Tidsskr., 35 1), 2128.

Willis, I. C., M.J. Sharp and K. S. Richards. 1990. Conliguration of the drainage system of Midtdalsbreen, Norway, as indicated by dyetracing experiments. \%. Glaciol.. 36 122, 89101. 